\title{
Variant SNPs at the microRNA complementary site in the $B$ 7-H1 3'-untranslated region increase the risk of non-small cell lung cancer
}

\author{
WENWEN DU ${ }^{1,2^{*}}$, JIANJIE ZHU ${ }^{1,2^{*}}$, YANBIN CHEN ${ }^{1,2^{*}}$, YUANYUAN ZENG $^{1,2}$, DAN SHEN ${ }^{1,2}$, \\ NAN ZHANG ${ }^{1,2}$, WEIWEI NING ${ }^{1,2}$, ZEYI LIU ${ }^{1,2}$ and JIAN-AN HUANG ${ }^{1,2}$ \\ ${ }^{1}$ Department of Respiratory Medicine, The First Affiliated Hospital of Soochow University; \\ ${ }^{2}$ Institute of Respiratory Diseases, Soochow University, Suzhou, Jiangsu 215006, P.R. China \\ Received July 7, 2016; Accepted May 5, 2017
}

DOI: $10.3892 / \mathrm{mmr} .2017 .6902$

\begin{abstract}
Single nucleotide polymorphisms (SNPs) in microRNA-binding sites located in the 3'-untranslated region (UTR) of target genes can have an effect on the interaction of microRNA-mediated regulation, which results in changes in the expression levels of target genes ultimately associated with cancer risk and patient prognosis. However, the role of SNPS at the 3'-UTR of B7-H1 in the susceptibility of non-small cell lung cancer (NSCLC) remains to be fully elucidated. In the present study, SNPs with a minor allele frequency $>10 \%$, which were located at the microRNA complementary site in the PD-L1 3'-UTR, were selected via bioinformatic prediction using Ensembl and miRanda 2010. A total of three SNPs were selected, s2297136, rs4143815 and rs4742098, in the 3'-UTR of B7-H1. The rs2297136 and rs4742098 SNPs exhibited significant differences between 320 patients with NSCLC and 199 healthy individuals, respectively $(\mathrm{P}<0.001$ and $\mathrm{P}=0.007)$. For the rs2297136 SNP, the AG genotype was significantly associated with evaluation of the risk of NSCLC, compared the AA genotype [odds ratio $(\mathrm{OR})=2.287 ; 95 \%$ confidence interval $(95 \%$ CI $)=1.558-3.358]$. Similarly, for the rs4742098 SNP, the AG genotype differed from the AA genotype on evaluation of the risk of NSCLC $(\mathrm{OR}=1.599 ; 95 \% \mathrm{CI}=1.027-2.488)$. Dual-luciferase reporter assays showed that rs2297136 and rs4742098 in the B7-H1 3'-UTR contributed to the occurrence of NSCLC through disrupting the interaction between
\end{abstract}

Correspondence to: Professor Jian-An Huang or Professor Zeyi Liu, Department of Respiratory Medicine, The First Affiliated Hospital of Soochow University, 188 Shizi Street, Suzhou, Jiangsu 215006, P.R. China

E-mail: huang_jian_an@yeah.net

E-mail: liuzeyisuda@163.com

*Contributed equally

Key words: B7-H1, single nucleotide polymorphism, microRNA, non-small cell lung cancer
miR-296-5p, miR-138 and B7-H1 mRNA. These results indicated that genetic polymorphisms affecting the expression of B7-H1 modified cancer susceptibility.

\section{Introduction}

Lung cancer is one of the leading causes of cancer-associated mortality. Non-small cell lung cancer (NSCLC) makes up $\sim 80 \%$ of lung cancer cases (1). Multiple factors are involved in the development of lung cancer, particularly environmental and genetic factors. Although novel diagnostic and therapeutic strategies are under development, the prognosis of lung cancer remains poor, with the five-year overall survival rate $<16 \%$ worldwide, due to early distant metastasis and local invasion (2).

$B 7-H 1$, also known as programmed-death ligand 1 (PD-L1) was first identified in 1999 and belongs to the B7 superfamily of coinhibitory molecules. It is crucial as a negative regulator for immune evasion of tumors, inhibiting $\mathrm{T}$ cell activation and proliferation by engaging with the PD-1 receptor $(3,4)$. Previous studies have confirmed that higher mRNA expression levels of $B 7-H 1$ are found in human non-lymphoid tissues, compared with low or negligible protein expression levels in these tissues, which has been observed in activated lymphocytes, including T cells, B cells and macrophage cells, previously $(3,5)$. This observation indicated that post-transcriptional regulation may be involved in regulating the expression of $B 7-H 1$. Previous studies have reported that the phosphatase and tensin homolog/phosphatidylinositol-3-kinase pathway (6) and microRNA (miR)-513 (7) are important in the post-transcriptional regulation of the cell surface expression of B7-H1. Of note, Wang et al identified the functional single nucleotide polymorphism (SNP) rs414815 within the miR-570 seed binding sequence in the 3'-untranslated region (3'-UTR) of PD-L1 mRNA, which affected its expression in gastric cancer (8).

MicroRNAs (miRNAs) are endogenous non-coding RNAs consisting of 19-24 nucleotides, which bind to complementary sites in the 3'-UTR of target messenger RNAs (mRNAs) to regulate diverse biological functions, including cell differentiation, proliferation, apoptosis and DNA repair (9-11). 
Therefore, it has been suggested that miRNAs contribute to the pathogenesis of various clinical diseases, including cancer. The association between miRNAs and their target genes is complicated; one miRNA has the ability to bind to various mRNAs simultaneously, whereas the opposite is not observed $(12,13)$. Therefore, genetic variations, including those of miRNAs or the 3'-UTR of target mRNAs, can alter their interaction (14). There is increasing evidence suggesting that SNPs in miRNA target genes, which represent genetic variants of the miRNA-binding region, can modify miRNA binding, affecting the risk and susceptibility of patients to cancer, including gastric cancer (15), ovarian carcinoma (16), colorectal cancer $(17,18)$ and skin carcinoma (19). However, no studies have focused on SNPs in the 3-UTR of the B7-H1 gene or its association with the risk of NSCLC.

Based on the aforementioned findings, three SNPs of the miRNA-binding sites in the 3'-UTR of the B7-H1 gene, including rs2297136, rs4143815 and rs4742098, were selected for examination. The present case-control study was performed to evaluate the relevance of these SNPs in terms of the risk of NSCLC and its clinical characteristics.

\section{Materials and methods}

Study population. A total of 519 cases were enrolled, including 320 patients with NSCLC and 199 healthy controls, from The First Affiliated Hospital of Soochow University (Suzhou, China) between March 2010 and November 2014. The diagnosis of lung cancer was histologically confirmed. For the patients with lung cancer, several detailed clinical pathological characteristics, including histological type, depth of tumor infiltration, distant metastasis, lymph node metastasis and tumor-node-metastasis (TNM) stage, are listed in Table I. None of the 199 age- and sex-matched healthy control individuals had any serious respiratory disease or familial history of cancer. At recruitment, written informed consent was obtained from participants. The present study was approved by the Ethics Committee of the First Affiliated Hospital of Soochow University.

Genomic DNA sample extraction. Total genomic DNA from venous blood samples of the patients and controls were extracted at the time of recruitment using a phenol/chloroform method. The isolated DNA was stored at $-20^{\circ} \mathrm{C}$ in TE buffer containing $10 \mathrm{mmol} / \mathrm{l}$ Tris- $\mathrm{HCl}$ and $1 \mathrm{mmol} / \mathrm{l}$ EDTA (pH 8.0).

Cell lines and cell culture. The A549 lung adenocarcinoma cell line was selected and obtained from the Shanghai Institutes of Biological Sciences Cell Bank (Shanghai, China) for the present study. These cells were cultured in Hyclone RPMI 1640 medium (HyClone; GE Healthcare Life Sciences, Logan, UT, USA) supplemented with $10 \%$ fetal bovine serum (FBS; Gibco; Thermo Fisher Scientific, Inc., Waltham, MA, USA), L-glutamine and antibiotics (Invitrogen; Thermo Fisher Scientific, Inc.) at $37^{\circ} \mathrm{C}$ in a humidified incubator with $5 \% \mathrm{CO}_{2}$. Cells in the logarithmic growth phase were used for experiments.

miRNA SNP selection and genotyping assays. Firstly, a search was performed of all potentially functional SNPs in the
3'-UTR region of the $B 7-H 1$ gene from the dbSNP Ensembl BUILD129, Ensembl, TSC1 and HGVbase1 databases using Ensembl (www.ensembl.org). The miRNA target prediction software programs miRanda 2010 (www.microrna.org) and TargetScan v5.1 (targetscan.org) were used to predict the possible miRNA-binding sites in the 3'-UTR of the $B 7-H 1$ gene. Among these, SNPs with a minor allele frequency (MAF) $<0.05$ were excluded. The SNPs located in the putative miRNA binding sites were regarded as candidate miRNA SNPs.

The genotypes of the specific primers were then designed to amplify DNA segments of B7-H1 3'-UTR using allele-specific oligonucleotide polymerase chain reaction (PCR) to determine unknown genotypes. The $20 \mu \mathrm{l} \mathrm{PCR}$ reaction mixture consisted of $10.55 \mu \mathrm{l} \mathrm{H}_{2} \mathrm{O}, 2 \mu \mathrm{l} 10 \mathrm{X}$ buffer, $1.2 \mu \mathrm{l} \mathrm{MgCl}_{2}, 0.8 \mu \mathrm{l}$ forward primer, $0.8 \mu \mathrm{l}$ reverse primer, $0.4 \mu \mathrm{l} \mathrm{dNTP,} 0.25 \mu \mathrm{l} \mathrm{Taq}$ DNA polymerase and $1 \mu \mathrm{l}$ genomic DNA model. The PCR cycling procedure comprised of an initial predenaturation step of $5 \mathrm{~min}$ at $94^{\circ} \mathrm{C}$, followed by 35 cycles of denaturation at $94^{\circ} \mathrm{C}$ for $30 \mathrm{sec}$, annealing at $55^{\circ} \mathrm{C}$ for $30 \mathrm{sec}$, and extension at $70^{\circ} \mathrm{C}$ for $30 \mathrm{sec}$ to form double-strand DNA. Elongation at $70^{\circ} \mathrm{C}$ for $7 \mathrm{~min}$ and cooling at $4^{\circ} \mathrm{C}$ for $10 \mathrm{~min}$ were performed to render DNA product stable.

3'-UTR luciferase reporter assays. To generate the luciferase reporter, two sequences containing the potential binding sites for miR-324-5p, miR-296-5p and miR-138, the 3'-UTRs of B7-H1 mRNA (rs2297136 and rs4742098 SNPs) were synthesized (Genewiz, Inc., Suzhou, China), corresponding either to the A haplotype or to the $\mathrm{G}$ haplotype. The two sequences were cloned into the psiCHECK2 vector downstream of the firefly luciferase gene, respectively.

For the luciferase reporter assays, the A549 cells were plated at $5 \times 10^{4}$ cells per well in a 24 -well plate and were transfected 24 h later with Lipofectamine 2000 (Invitrogen; Thermo Fisher Scientific, Inc.) according to the manufacturer's protocol. Each co-transfection reaction contained $200 \mathrm{ng}$ of psiCHECK 2 constructs, $50 \mathrm{nM}$ of chemically synthesized miR-324-5p mimic, miR-296-5p mimic, miR-138 mimic, or negative control miRNA, the latter serving as a normalizing control, and the psiCHECK2-control vector as a blank control. The transfected A549 cells were maintained in RPMI 1640 medium with $10 \%$ FBS. Each transfection was performed in triplicate. Following incubation for $48 \mathrm{~h}$, the cells were collected and analyzed for luciferase activity using the dual-luciferase reporter assay system (Promega Corporation, Madison, WI, USA).

Statistical analysis. All statistical data were obtained using SPSS software (version 11.5; SPSS, Inc., Chicago, IL, USA). The Hardy-Weinberg equilibrium (HWE) was determined using the goodness-of-fit $\chi^{2}$ test. Differences in genotype and allelic frequencies of the involved SNPs between patients with lung cancer and controls, and associations between SNPs and clinical characteristics were calculated using $\chi^{2}$ tests. The association between SNPs and lung cancer risk were estimated according to the odds ratio (OR) and $95 \%$ confidence interval (95\% CI) using multivariate logistic regression. All statistical tests were two-sided. $\mathrm{P}<0.05$ was considered to indicate a statistically significant difference. 
Table I. Characteristics of participants in the case-control study.

\begin{tabular}{|c|c|c|c|}
\hline Characteristic & Variable & NSCLC n=320 (\%) & Control $n=199(\%)$ \\
\hline \multirow[t]{2}{*}{ Age, years } & $<65$ & $165(51.6)$ & $132(66.3)$ \\
\hline & $\geq 65$ & $155(48.4)$ & $67(33.7)$ \\
\hline \multirow[t]{2}{*}{ Sex } & Male & $240(75.0)$ & $121(60.8)$ \\
\hline & Female & $80(25.0)$ & $78(39.2)$ \\
\hline \multirow[t]{3}{*}{ Pathological type } & Adenocarcinoma & $163(50.9)$ & - \\
\hline & Squamous cell carcinoma & $139(43.4)$ & - \\
\hline & Other & $18(5.7)$ & - \\
\hline \multirow[t]{4}{*}{ Depth of tumor infiltration } & $\mathrm{T} 1$ & $42(13.1)$ & - \\
\hline & $\mathrm{T} 2$ & 70 (21.9) & \\
\hline & $\mathrm{T} 3$ & $58(18.1)$ & \\
\hline & $\mathrm{T} 4$ & $150(46.9)$ & \\
\hline \multirow[t]{2}{*}{ Lymph node metastasis } & Negative & $53(16.6)$ & \\
\hline & Positive & $267(83.4)$ & \\
\hline \multirow[t]{2}{*}{ Distant metastasis } & Negative & $105(32.8)$ & \\
\hline & Positive & $215(67.2)$ & \\
\hline \multirow[t]{4}{*}{ TNM stage } & $\mathrm{I}$ & $40(12.5)$ & \\
\hline & II & $20(6.3)$ & \\
\hline & III & $51(15.9)$ & \\
\hline & IV & $209(65.3)$ & \\
\hline
\end{tabular}

NSCLC, non-small cell lung cancer; TNM, tumor-node-metastasis.

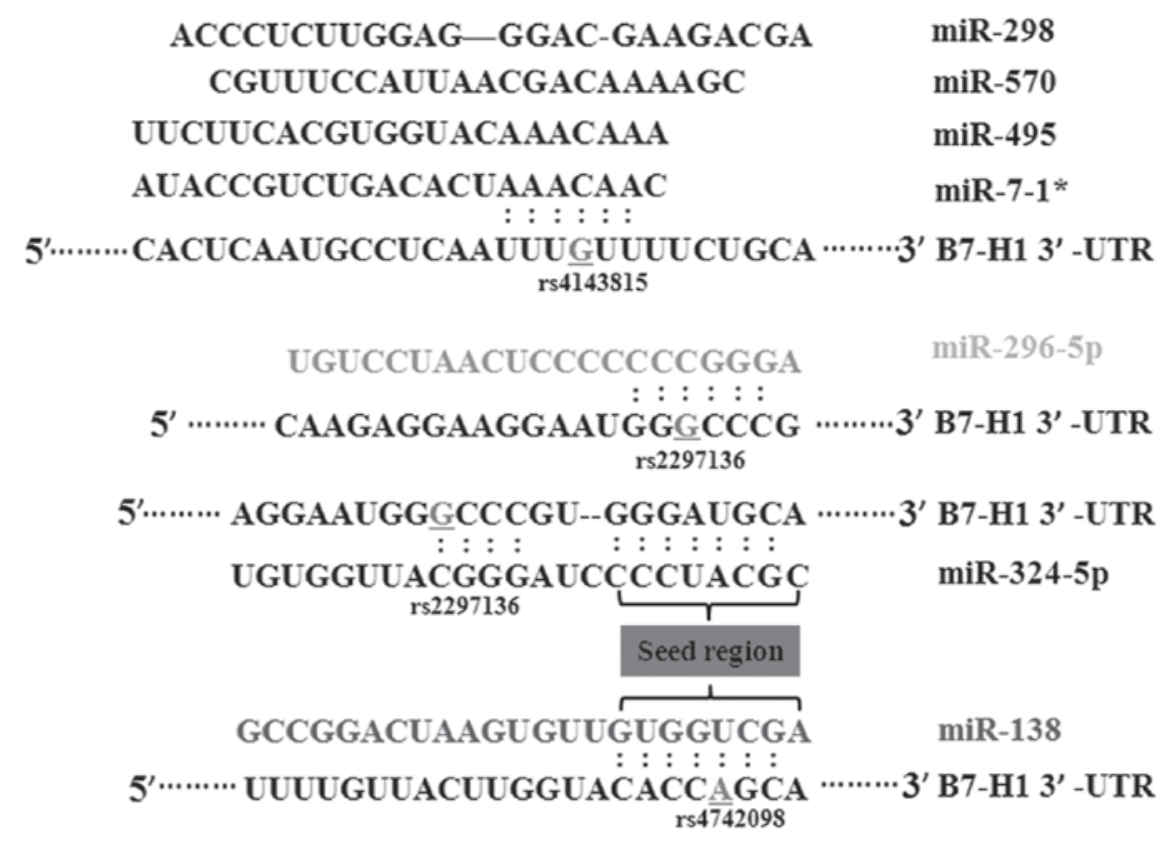

Figure 1. Schematic of $B 7-H 1$ mRNA harboring putative binding sites of miR-298, miR-570, miR-495, miR-7-1*, miR-296-5p, miR-324-5p and miR-138 and three single nucleotide polymorphism in the 3'-UTR. The rs2297136 G>A and rs4742098 A>G SNPs are located within the 'seed region' of the miR-296-5p and miR-138, respectively. miR, microRNA; 3'-UTR, 3'-untranslated region.

\section{Results}

Basic characteristics of subjects. A total of 320 patients with NSCLC were enrolled in the present study. The clinical and pathological variants are listed in Table I. The control group consisted of 199 individuals with no malignant respiratory disease.

Polymorphic 3'-UTR of the B7-H1 gene. Three SNPs of the microRNA-binding sites in the 3'-UTR region of the B7-HI 
Table II. SNPs located in the 3'-untranslated region of $B 7-H 1$ and associated miRNAs.

\begin{tabular}{|c|c|c|c|c|}
\hline SNP & Nucleotide change & $\mathrm{MAF}^{\mathrm{a}}$ & Position on $\mathrm{B} 7-\mathrm{HI}$ & miRNA \\
\hline rs2297136 & $\mathrm{G}>\mathrm{A}$ & $\mathrm{G}=0.3613$ & 93 & $\begin{array}{l}\text { miR-324-5p } \\
\text { miR-296-5p }\end{array}$ \\
\hline rs4143815 & $\mathrm{G}>\mathrm{C}$ & $\mathrm{G}=0.3320$ & 395 & $\begin{array}{l}\text { miR-570 miR-7-1* } \\
\text { miR-495 miR-298 }\end{array}$ \\
\hline rs4742098 & $A>G$ & $\mathrm{G}=0.3306$ & 2,635 & miR-138 \\
\hline
\end{tabular}

${ }^{a}$ Minor allele frequency in the Chinese population. NSCLC, non-small cell lung cancer; SNP, single nucleotide polymorphism; miRNA, microRNA.
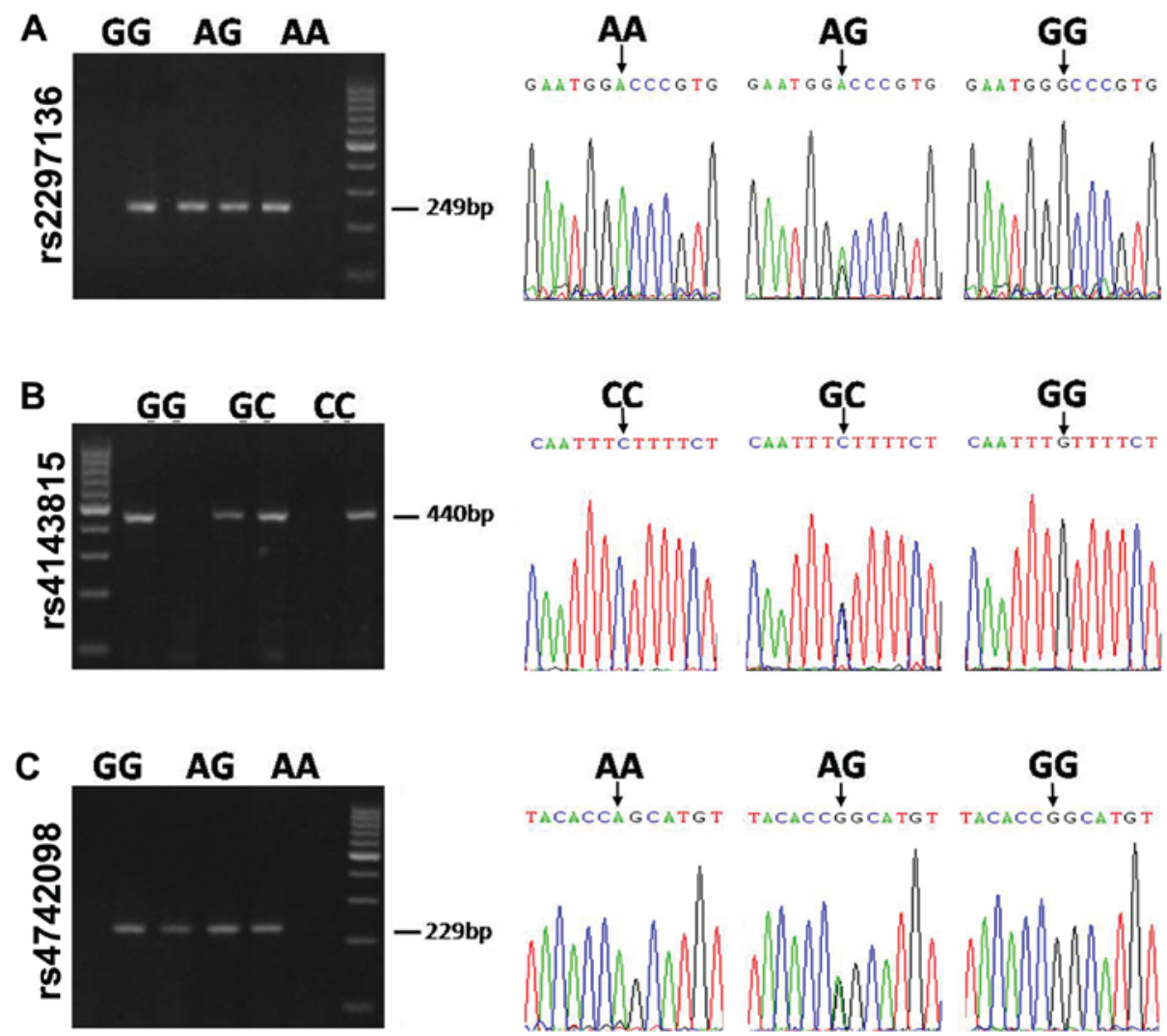

Figure 2. Typical genotyping results of single nucleotide polymorphism using allele-specific oligonucleotide polymerase chain reaction and DNA sequencing. (A) rs2297136; (B) rs4143815; (C) rs474209.

gene, including rs2297136, rs4143815 and rs4742098, were selected from the dbSNP BUILD129, Ensembl, TSC1 and HGVbase15 databases. With the assistance of miRanda and TargetScan v5.1 prediction software, several miRNAs were identified with the potential ability to bind to the 3'-UTR region of the $B 7-H 1$ gene. From these results, it was found that miR-324-5p, miR-296-5p were able to bind to the rs2297136 SNP. miR-570, miR-7-1*, miR-495 and miR-298 had certain binding sites with the rs4143815 SNP. The rs4742098 SNP was located in the binding sites of miR-138 (Fig. 1). The detailed SNP IDs, wild-type and mutated gene transformations, MAF and miRNAs are shown in Table II. To confirm the findings, the three SNPs were genotyped using a sequencing method. The typical genotyping results are presented in Fig. 2.
Association between SNPs in the B7-H1 gene and risk of NSCLC. All patients with NSCLC and healthy controls were successfully genotyped for the three SNPs. The HWE was determined using the goodness-of-fit $\chi^{2}$ test, and no deviations were detected from the three SNPs, which had values of $0.133,0.127$ and 1.771 . The overall genotype distributions and allele frequencies of these three SNPs in all individuals are presented in Table III.

The results of the two-sided $\chi^{2}$ test revealed that the genotype frequencies of the rs2297136 and rs4742098 SNPs showed significant differences between cases and controls $(\mathrm{P}<0.001$ and $\mathrm{P}=0.007$, respectively). In terms of rs2297136 and rs4742098 the SNPs, individuals carrying the AG genotype showed a significant association with risk of NSCLC $(\mathrm{OR}=2.287 ; 95 \% \mathrm{CI}=1.558-3.358 ; \mathrm{P}<0.001)$, 
Table III. Genotype distributions of SNPs in the cases of NSCLC and controls, and risk estimate.

\begin{tabular}{|c|c|c|c|c|c|c|c|}
\hline SNP & Genotype & $\begin{array}{c}\text { NSCLC } \\
\mathrm{n}=320(\%)\end{array}$ & $\begin{array}{c}\text { Control } \\
\mathrm{n}=199(\%)\end{array}$ & P-value ${ }^{a}$ & $\begin{array}{l}\text { HWE } \\
\text { P-value }\end{array}$ & $\begin{array}{c}\text { OR } \\
(95 \% \mathrm{CI})\end{array}$ & P-value \\
\hline \multirow[t]{4}{*}{ rs2297136 } & AA & $83(25.9)$ & $84(42.2)$ & \multirow[t]{4}{*}{$<0.001$} & \multirow[t]{4}{*}{0.133} & 1 (reference) & \\
\hline & AG & $226(70.6)$ & $100(50.2)$ & & & $2.287(1.558-3.358)$ & $<0.001$ \\
\hline & GG & $11(3.5)$ & $15(7.5)$ & & & $0.742(0.322-1.711)$ & 0.532 \\
\hline & $\mathrm{G}$ allele carrier & $237(74.1)$ & $115(57.8)$ & & & $2.086(1.432-3.039)$ & $<0.001$ \\
\hline \multirow[t]{4}{*}{ rs4143815 } & $\mathrm{CC}$ & $123(38.4)$ & $79(37.8)$ & \multirow[t]{4}{*}{0.439} & \multirow[t]{4}{*}{5.343} & 1 (reference) & \\
\hline & GC & $145(45.3)$ & $80(41.5)$ & & & $1.076(0.723-1.601)$ & 0.719 \\
\hline & GG & $52(16.3)$ & $40(20.7)$ & & & $1.296(0.783-2.145)$ & 0.312 \\
\hline & $\mathrm{G}$ allele carrier & 197 (61.6) & $120(62.2)$ & & & $1.054(0.734-1.515)$ & 0.782 \\
\hline \multirow[t]{4}{*}{ rs4742098 } & $\mathrm{AA}$ & $67(20.9)$ & $51(25.6)$ & \multirow[t]{4}{*}{0.007} & \multirow[t]{4}{*}{1.771} & 1 (reference) & \\
\hline & $\mathrm{AG}$ & $189(59.1)$ & $90(45.2)$ & & & $1.599(1.027-2.488)$ & 0.037 \\
\hline & GG & $64(20.0)$ & $58(29.2)$ & & & $0.840(0.505-1.390)$ & 0.502 \\
\hline & $\mathrm{G}$ allele carrier & $253(79.1)$ & $148(74.4)$ & & & $1.301(0.858-1.974)$ & 0.237 \\
\hline
\end{tabular}

${ }^{a}$ Two-sided $\chi^{2}$ test for genotype frequency distribution. NSCLC, non-small cell lung cancer; SNP, single nucleotide polymorphism; HWE, Hardy-Weinberg equilibrium.

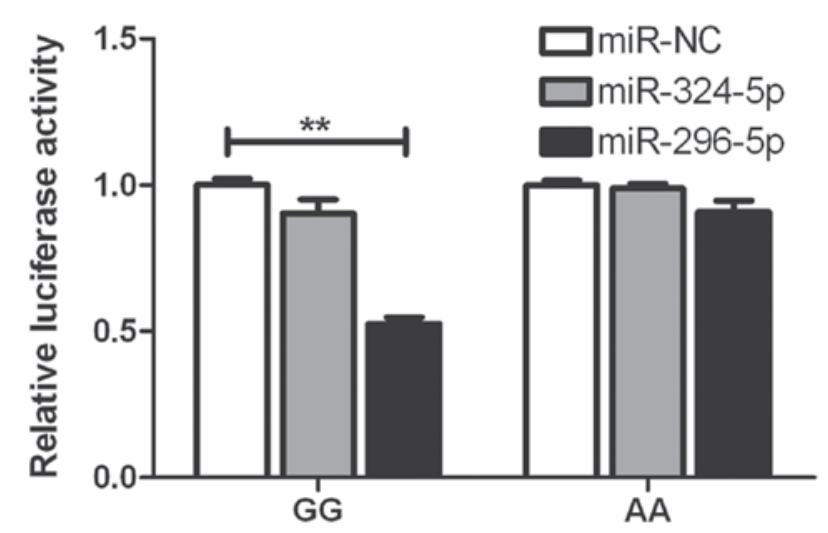

Figure 3. Effects of rs2297136 single nucleotide polymorphism on the inhibitory role of miR-324-5p, miR-296-5p on the expression of B7-H1. Expression of the G-allele-specific psiCHECK 2 construct was inhibited by miR-296-5p $\left({ }^{* *} \mathrm{P}=0.003\right)$. The $\mathrm{A}$ and $\mathrm{G}$ allele-specific psiCHECK2 constructs were not suppressed by miR-324-5p ( $\mathrm{P}=0.140$ and $\mathrm{P}=0.624$, respectively). miR, microRNA; NC, negative control.

compared with those carrying the AA genotype ( $\mathrm{OR}=1.599$; 95\% CI=1.027-2.488; $\mathrm{P}=0.037)$, respectively. As for the rs2297136 SNP alone, G allele carriers (individuals with the AG or GG genotype) were also at a significantly higher risk of NSCLC, compared with those carrying A allele homozygotes $(\mathrm{OR}=2.086 ; 95 \% \mathrm{CI}=1.432-3.039$; $\mathrm{P}<0.001)$. No significant differences in genotype distributions or allele frequencies were found in the rs4143815 SNP between patients and healthy controls $(\mathrm{P}=0.439)$.

Stratified analyses of the associations between each SNP genotypes and the clinical characteristics of NSCLC were then performed (Tables IV-VI). Significant associations were found in rs2297136 genotypes with lymph node metastasis and distant metastasis. Compared with the AA homozygote, individuals with the GG homozygote were less likely to exhibit lymph node metastasis $(\mathrm{P}=0.049)$ and more likely to exhibit

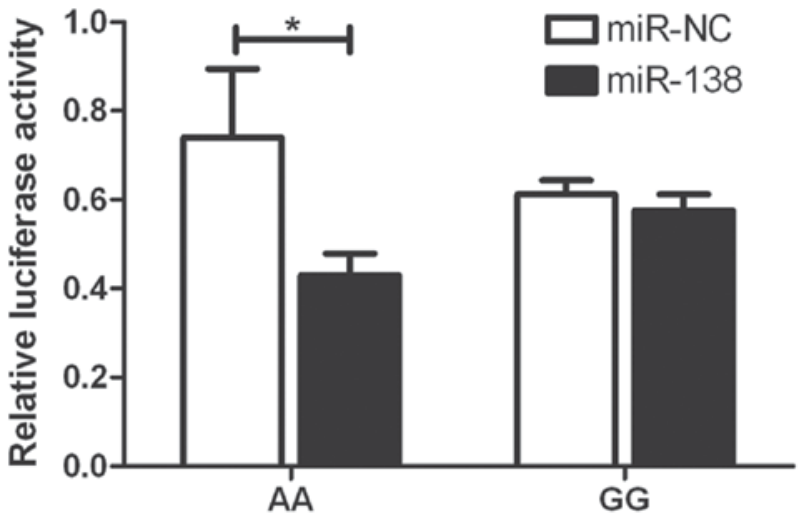

Figure 4. Effect of the rs4742098 single nucleotide polymorphism on the interaction between the $B 7-H 1$ 3'-untranalsated region and miR-138. A statistically significant increase in luciferase expression was found with the A allele, compared with the $\mathrm{G}$ allele $\left({ }^{*} \mathrm{P}=0.029\right)$. miR, microRNA; NC, negative control.

distant metastases $(\mathrm{P}=0.035$; Table IV). For rs4742098, there were associations between the variant genotypes and depth of tumor infiltration (Table VI). However, no statistically significant associations were found between the rs4143815 genotypes and clinical characteristics (Table V).

Functional relevance of $r s 2297136$ and $r s 4742098$ in the interaction between miRNA and the expression of B7-H1. To determine whether the inhibitory roles of miR-324-5p, miR-296-5p and miR-138 are affected by rs2297136 and rs4742098, respectively, psiCHECK2 vectors were constructed, including wild-type and mutated genotypes, which were then co-transfected with these miRNAs into A549 cells. It was found that the expression of the G-allele-specific psiCHECK2 construct was significantly suppressed by miR-296-5p in terms of the rs2297136 SNP (Fig. 3). With the rs4742098 SNP, the expression of A-allele-specific psiCHECK 2 construct was 


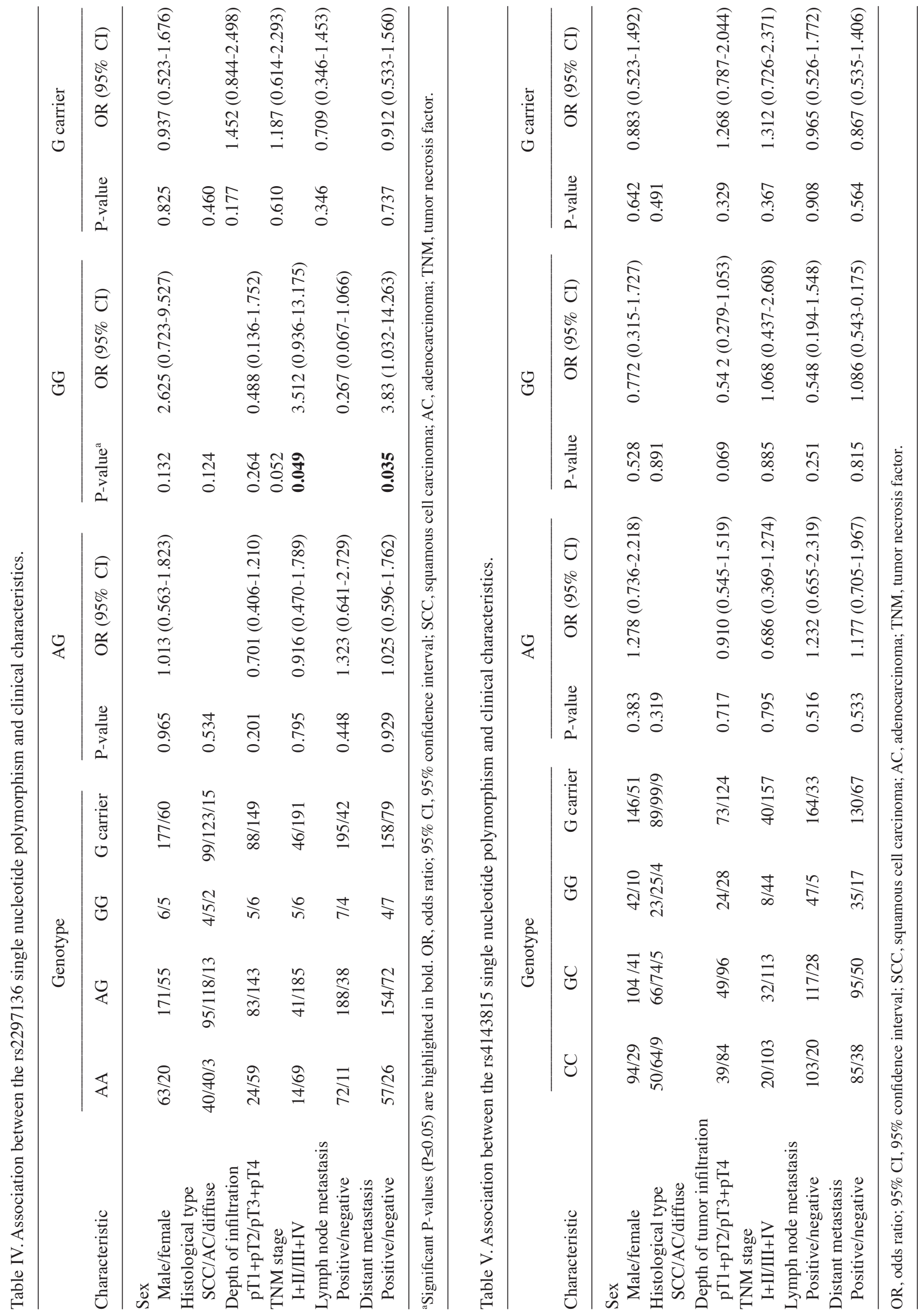


inhibited by miR-138 (Fig. 4). These findings indicated that the two miRNAs inhibited the expression of $\mathrm{B} 7-\mathrm{Hl}$ by binding to the two SNPs.

\section{Discussion}

To the best of our knowledge, genetic factors are considered to contribute to the development of tumorigenesis in lung cancer. However, the identification of prognostic markers for the risk of lung cancer from the miR-SNP perspective is a novel field in the progress of the cancer research (20). Based on this, the present study aimed to investigate the potential association between three SNPs of the miRNA-binding site in the 3'-UTR region of the B7-H1 gene (rs2297136, rs4143815 and rs4742098) and the risk of NSCLC through a case-control approach. The results provided evidence that rs2297136 and rs4742098 are functional SNPs, which contain genetic variants associated with the increased risk of NSCLC. In addition, the analysis revealed that these SNPs had significant associations with clinicopathological features, including depth of tumor infiltration, distant metastasis, lymph node metastasis and TNM stage. Therefore, these two SNPs may be possible prognostic markers for NSCLC.

B7- $H 1$ exists as an inhibitory regulator of cosignaling molecules involved in the pathway of activation of $\mathrm{T}$ lymphoid cells. It can be expressed in diverse tissues, lymphoid cells and nonlymphoid tissues, including smooth muscle cells, epithelial cells and endothelial cells, in response to inflammatory cytokines, including interferon (IFN)- $\gamma$, IFN- $\alpha$ and interleukin-1 $(3,21,22)$. It can also be induced in human solid tumors and is commonly associated with poor prognosis, larger tumor size, distant metastasis, deeper tumor infiltration, increased lymph node metastasis and TNM stage, due to its ability to inhibit T-cell proliferation and suppress its function to avoid immune surveillance (23). Therefore, the tumor-associated $B 7-H 1$ gene appears to have an important role in tumor occurrence, promotion, invasion, angiogenesis and metastasis $(24,25)$.

miRNAs are involved in the regulation of a range of biological function, including cell differentiation, proliferation, apoptosis and DNA repair. Therefore, it has been suggested that it contributes to the pathogenesis of various clinical diseases, including cancer $(26,27)$. Previous investigations have been performed to examine the associations of SNPs in miRNAs target genes, which locate in the miRNA-binding region and affect the susceptibility of cancer. It has been reported that a genetic mutation within the 3'-UTR region of the TNFAIP2 gene (rs8126) contributes to the risk of esophageal squamous cell carcinoma (28). In addition, the miRNA-135a/b binding site polymorphism in the CD133 3'-UTR confers decreased risk and favorable prognosis in lung cancer by reducing the expression of CD133 (29). A genetic variation in the miRNA target site of the KRT81 gene has also been associated with survival rates in early-stage NSCLC (30), and the reduced expression of let-7 miRNAs in human lung cancer has been association with shortened postoperative survival rates (31).

In the present study, genotyping of three SNPs (rs2297136, rs4143815 and rs4742098) of the miRNA-binding sites in the 3'-UTR region of the $B 7-H 1$ gene was performed in 320 patients with NSCLC and 199 healthy controls, to 
determine the effect of these SNPs on the risk of NSCLC. Following genotyping, significant differences were found between the cases and controls in rs2297136 and rs4742098 SNPs $(\mathrm{P}<0.001$ and $\mathrm{P}=0.007)$. For these two SNPs, individuals carrying the AG genotype showed significant associations with the risk of NSCLC, $(\mathrm{OR}=2.287 ; 95 \% \mathrm{CI}=1.558-3.358$; $\mathrm{P}<0.001)$, as did those carrying the AA genotype (OR=1.599, 95\% CI=1.027-2.488, $\mathrm{P}=0.037)$. Furthermore, for the SNP rs2297136 alone, individuals carrying genotype AA has a decreased risk of developing NSCLC, compared with individuals carrying the $\mathrm{G}$ variant allele, including $\mathrm{AG}$ and GG carriers $(\mathrm{OR}=2.086 ; 95 \% \mathrm{CI}=1.432-3.039$; $\mathrm{P}<0.001)$. The present study then focused on clinical characteristics, the GG homozygote of rs2297136 was significantly more prevalent in patients with a reduced presence of lymph node metastasis $(\mathrm{P}=0.049)$, and higher prevalence of distant metastasis $(\mathrm{P}=0.035)$, compared with the AA homozygote. As for the rs4742098 SNP, all mutated alleles, including the AG, GG and $\mathrm{G}$ carriers, showed significant association with deeper infiltration $(\mathrm{P}=0.009, \mathrm{P}=0.006$ and $\mathrm{P}=0.003$, respectively).

SNPs in the 3'UTR region of the $B 7-H 1$ gene can affect the interaction of miRNAs and complementary sites, which can result in the reduced expression of B7-H1 (32). In terms of the miRNAs of interest in the present study, miR-324-5p, miR-296-5p and miR-138 were selected to examine the association with the rs2297136 and rs4742098 SNPs. It was found that the expression of the G-allele-specific psiCHECK2 construct was significantly suppressed by miR-296-5p in terms of the rs2297136 SNP. With the rs4742098 SNP, the expression of the A-allele-specific psiCHECK2 construct was inhibited by miR-138. This may be a vital step in the mechanism regulating the expression of $\mathrm{B} 7-\mathrm{HI}$.

There were a number of limitations in the present constructed case-control study. Firstly, the number of DNA samples from all patients with NSCLC and healthy controls available for the present study were low to a certain degree, therefore, the analyses performed from these data may show minimal deviation from the average. Secondly, all the samples collected were from the same hospital, with the outcome that inherent selection bias may exist, therefore a larger population-based study may be considered to validate these results in the future.

In conclusion, the present study demonstrated that the functional polymorphisms of the miRNA-binding sites in the 3'-UTR region of the B7-HI gene were significantly associated with higher risks of lung cancer, distant metastasis, lymph node metastasis and deep infiltration (rs2297136 and rs4742098). These results support the hypothesis that genetic variants can interrupt the miRNA-mediated regulation of a target gene, which may become a possible prognostic marker for the prediction of NSCLC risk.

\section{Acknowledgements}

This study was supported by grants from the National Natural Science Foundation of China (grant no. 31270940 to Professor Jian-an Huang), the Jiangsu Provincial Special Program of Medical Science (grant no. BL2012023) and the Clinical Key Specialty Project of China and Clinical Medical Center of Suzhou (grant no. Szzx201502).

\section{References}

1. Jemal A, Center MM, DeSantis C and Ward EM: Global patterns of cancer incidence and mortality rates and trends. Cancer Epidemiol Biomarkers Prev 19: 1893-1907, 2010.

2. Siegel R, Naishadham D and Jemal A: Cancer statistics, 2012. CA Cancer J Clin 62: 10-29, 2012.

3. Dong H, Strome SE, Salomao DR, Tamura H, Hirano F, Flies DB Roche PC, Lu J, Zhu G, Tamada K, et al: Tumor-associated B7-H1 promotes T-cell apoptosis: A potential mechanism of immune evasion. Nat Med 8: 793-800, 2002.

4. Greenwald RJ, Freeman GJ and Sharpe AH: The B7 family revisited. Annu Rev Immunol 23: 515-548, 2005.

5. Zou W and Chen L: Inhibitory B7-family molecules in the tumour microenvironment. Nat Rev Immunol 8: 467-477, 2008.

6. Parsa AT, Waldron JS, Panner A, Crane CA, Parney IF, Barry JJ, Cachola KE, Murray JC, Tihan T, Jensen MC, et al: Loss of tumor suppressor PTEN function increases B7-H1 expression and immunoresistance in glioma. Nat Med 13: 84-88, 2007.

7. Gong AY, Zhou R, Hu G, Li X, Splinter PL, O'Hara SP, LaRusso NF, Soukup GA, Dong $H$ and Chen XM: MicroRNA-513 regulates B7-H1 translation and is involved in IFN-gamma-induced B7-H1 expression in cholangiocytes. J Immunol 182: 1325-1333, 2009.

8. Wang W, Li F, Mao Y, Zhou H, Sun J, Li R, Liu C, Chen W, Hua D and Zhang X: A miR-570 binding site polymorphism in the B7-H1 gene is associated with the risk of gastric adenocarcinoma. Hum Genet 132: 641-648, 2013

9. Hoon DS, Ferris R, Tanaka R, Chong KK, Alix-Panabières C and Pantel K: Molecular mechanisms of metastasis. J Surg Oncol 103: 508-517, 2011.

10. Bartel DP: MicroRNAs: Genomics, biogenesis, mechanism, and function. Cell 116: 281-297, 2004.

11. Kent OA and Mendell JT: A small piece in the cancer puzzle: microRNAs as tumor suppressors and oncogenes. Oncogene 25: 6188-6196, 2006.

12. Brennecke J, Stark A, Russell RB and Cohen SM: Principles of microRNA-target recognition. PLoS Biol 3: e85, 2005.

13. Brodersen $\mathrm{P}$ and Voinnet $\mathrm{O}$ : Revisiting the principles of microRNA target recognition and mode of action. Nat Rev Mol Cell Biol 10: 141-148, 2009.

14. Makeyev EV and Maniatis T: Multilevel regulation of gene expression by microRNAs. Science 319: 1789-1790, 2008.

15. Song X, Zhong H, Zhou J, Hu X, Zhou Y, Ye Y, Lu X, Wang J, Ying B and Wang L: Association between polymorphisms of microRNA-binding sites in integrin genes and gastric cancer in Chinese Han population. Tumour Biol 36: 2785-2792, 2015.

16. Kim M, Chen X, Chin LJ, Paranjape T, Speed WC, Kidd KK, Zhao H, Weidhaas JB and Slack FJ: Extensive sequence variation in the 3' untranslated region of the KRAS gene in lung and ovarian cancer cases. Cell Cycle 13: 1030-1040, 2014. Zhao Y, Du Y, Zhao S and Guo Z: Single-nucleotide polymorphisms of microRNA processing machinery genes and risk of colorectal cancer. Onco Targets Ther 8: 421-425, 2015.

17. Zhao Y, Du Y, Zhao S and Guo Z: Single-nucleotide polymorphisms of microRNA processing machinery genes and risk of colorectal cancer. Onco Targets Ther 8: 421-5, 2015.

18. Ye P, Li Z, Jiang H and Liu T: SNPs in microRNA-binding sites in the ITGB1 and ITGB3 3'-UTR increase colorectal cancer risk. Cell Biochem Biophys 70: 601-607, 2014.

19. Cao Y, Zhang L, Ritprajak P, Tsushima F, Youngnak-Piboonratanakit P, Kamimura Y, Hashiguchi M and Azuma M: Immunoregulatory molecule B7-H1 (CD274) contributes to skin carcinogenesis. Cancer Res 71: 4737-4741, 2011.

20. Esquela-Kerscher A and Slack FJ: Oncomirs-microRNAs with a role in cancer. Nat Rev Cancer 6: 259-269, 2006.

21. Tsushima F, Tanaka K, Otsuki N, Youngnak P, Iwai H, Omura K and Azuma M: Predominant expression of B7-H1 and its immunoregulatory roles in oral squamous cell carcinoma. Oral Oncol 42: 268-274, 2006.

22. Lee SJ, Jang BC, Lee SW, Yang YI, Suh SI, Park YM, Oh S, Shin JG, Yao S, Chen L and Choi IH: Interferon regulatory factor- 1 is prerequisite to the constitutive expression and IFN-gamma-induced upregulation of B7-H1 (CD274). FEBS Lett 580: 755-762, 2006.

23. Blank C, Gajewski TF and Mackensen A: Interaction of PD-L1 on tumor cells with PD-1 on tumor-specific T cells as a mechanism of immune evasion: Implications for tumor immunotherapy. Cancer Immunol Immunother 54: 307-314, 2005. 
24. Keir ME, Butte MJ, Freeman GJ and Sharpe AH: PD-1 and its ligands in tolerance and immunity. Annu Rev Immunol 26 : 677-704, 2008

25. Youngnak-Piboonratanakit $\mathrm{P}$, Tsushima F, Otsuki N, Igarashi $\mathrm{H}$ Machida U, Iwai H, Takahashi Y, Omura K, Yokozeki H and Azuma M: The expression of B7-H1 on keratinocytes in chronic inflammatory mucocutaneous disease and its regulatory role. Immunol Lett 94: 215-222, 2004.

26. Bartel DP: MicroRNAs: Target recognition and regulatory functions. Cell 136: 215-233, 2009.

27. Ryan BM, Robles AI and Harris CC: Genetic variation in microRNA networks: The implications for cancer research. Nat Rev Cancer 10: 389-402, 2010.

28. Zhang J, Yu H, Zhang Y, Zhang X, Zheng G, Gao Y, Wang C and Zhou L: A functional TNFAIP2 3'-UTR rs8126 genetic polymorphism contributes to risk of esophageal squamous cell carcinoma. PLoS One 9: e109318, 2014.

29. Cheng M, Yang L, Yang R, Yang X, Deng J, Yu B, Huang D, Zhang S, Wang H, Qiu F, et al: A microRNA-135a/b binding polymorphism in CD133 confers decreased risk and favorable prognosis of lung cancer in Chinese by reducing CD133 expression. Carcinogenesis 34: 2292-2299, 2013.
30. Lee SY, Choi JE, Jeon HS, Hong MJ, Choi YY, Kang HG, Yoo SS, Lee EB, Jeong JY, Lee WK, et al: A genetic variation in microRNA target site of KRT81 gene is associated with survival in early-stage non-small-cell lung cancer. Ann Oncol 26: $1142-1148,2015$

31. Takamizawa J, Konishi H, Yanagisawa K, Tomida S, Osada H, Endoh H, Harano T, Yatabe Y, Nagino M, Nimura Y, et al: Reduced expression of the let-7 microRNAs in human lung cancers in association with shortened postoperative survival. Cancer Res 64: 3753-3756, 2004.

32. Yu Z, Li Z, Jolicoeur N, Zhang L, Fortin Y, Wang E, Wu M and Shen SH: Aberrant allele frequencies of the SNPs located in microRNA target sites are potentially associated with human cancers. Nucleic Acids Res 35: 4535-4541, 2007. 